\title{
Exposure and health impact evaluation based on simultaneous measurement of indoor and ambient $\mathrm{PM}_{2.5}$ in Haidian, Beijing ${ }^{\underline{\hbar}}$
}

\author{
Meng Qi ${ }^{a}$, Xi Zhu ${ }^{a}$, Wei Du ${ }^{a}$, Yilin Chen ${ }^{a}$, Yuanchen Chen ${ }^{a}$, Tianbo Huang ${ }^{a}$, \\ Xuelian Pan ${ }^{\mathrm{a}}$, Qirui Zhong ${ }^{\mathrm{a}}$, Xu Sun ${ }^{\mathrm{b}}$, Eddy Y. Zeng ${ }^{\mathrm{c}}$, Baoshan Xing ${ }^{\mathrm{d}}$, Shu Tao ${ }^{\mathrm{a},{ }^{*}}$ \\ a Laboratory for Earth Surface Processes, College of Urban and Environmental Sciences, Peking University, Beijing 100871, PR China \\ ${ }^{\mathrm{b}}$ Research Center for Eco-Environmental Sciences, CAS, Beijing, 100085, China \\ c School of Environment, Guangzhou Key Laboratory of Environmental Exposure and Health and Guangdong Key Laboratory of Environmental Pollution and \\ Health, Jinan University, Guangzhou 510632, China \\ ${ }^{\mathrm{d}}$ Stockbridge School of Agriculture, College of Natural Science, University of Massachusetts, Amherst, MA 01003-9246, USA
}

\section{A R T I C L E I N F O}

\section{Article history:}

Received 8 September 2016

Received in revised form

8 October 2016

Accepted 9 October 2016

Available online 18 October 2016

\section{Keywords:}

$\mathrm{PM}_{2.5}$

Indoor air

I/O

Modeling

Population exposure

\begin{abstract}
A B S T R A C T
Because people spend most of their time indoors, the characterization of indoor air quality is important for exposure assessment. Unfortunately, indoor air data are scarce, leading to a major data gap in risk assessment. In this study, $\mathrm{PM}_{2.5}$ concentrations in both indoor and outdoor air were simultaneously measured using on-line particulate counters in 13 households in Haidian, Beijing for both heating and non-heating seasons. A bimodal distribution of $\mathrm{PM}_{2.5}$ concentrations suggests rapid transitions between polluted and non-polluted situations. The $\mathrm{PM}_{2.5}$ concentrations in indoor and outdoor air varied synchronously, with the indoor variation lagging. The lag time in the heating season was longer than that in the non-heating season. The particle sizes in indoor air were smaller than those in ambient air in the heating season and vice versa in the non-heating season. $\mathrm{PM}_{2.5}$ concentrations in indoor air were generally lower than those in ambient air except when ambient concentrations dropped sharply to very low levels or there were internal emissions from cooking or other activities. The effectiveness of an air cleaner to reduce indoor $\mathrm{PM}_{2.5}$ concentrations was demonstrated. Non-linear regression models were developed to predict indoor air $\mathrm{PM}_{2.5}$ concentrations based on ambient data with lag time incorporated. The models were applied to estimate the overall population exposure to $\mathrm{PM}_{2.5}$ and the health consequences in Haidian. The health impacts would be significantly overestimated without the indoor exposure being taken into consideration, and this bias would increase as the ambient air quality improved in the future.
\end{abstract}

() 2016 Elsevier Ltd. All rights reserved.

\section{Introduction}

With the rapid economic growth in China, emissions of air pollutants have increased almost exponentially over the past several decades. As a result, air pollution in coastal regions, especially in northern Chinese cities, has attracted much attention. Severe haze episodes have occurred frequently in the Beijing-TianjinHebei region in recent years, and the air quality remains poor despite a series of measures taken recently (Zhao et al., 2015). Among various air pollutants, particulate matter (PM), especially

\footnotetext{
This paper has been recommended for acceptance by David Carpenter

* Corresponding author.

E-mail address: taos@pku.edu.cn (S. Tao).
}

$\mathrm{PM}_{2.5}$ (PM with mean aerodynamic size less than $2.5 \mu \mathrm{m}$ ) is of the most concern due to its strong adverse massive health impact. In addition to causing low visibility, the associations between $\mathrm{PM}_{2.5}$ exposure and many diseases, including cardiovascular and respiratory diseases, cancer and preterm birth, have been established (Pope and Dockery, 2006). According to the Global Burden of Disease Study, air pollution ranked third in terms of disabilityadjusted-life-years (DALYs) in China (GBD Compare, 2015). It was estimated that the annual mortality induced by $\mathrm{PM}_{2.5}$ exposure in three central districts of Beijing was more than 5000 during a period from 2001 to 2012 (Zheng et al., 2015).

Despite the fact that adult Chinese stay indoors for more than $80 \%$ of the time on average (Duan, 2013), ambient $\mathrm{PM}_{2.5}$ concentrations are usually used to evaluate heath consequences (Guo et al., 2016; Lepeule et al., 2012; Qian et al., 2016; Zheng et al., 
2015), likely for the following reasons: routine monitoring data are only available for ambient air; indoor air quality measurements are difficult to obtain; remote sensing-based observation is limited to the ambient environment; and only ambient air quality can be derived from atmospheric chemical transport modeling.

Evaluating the air quality in indoor environments is complicated because of large differences in household settings and the activities of residents. In many cases, indoor air quality is strongly affected by the penetration of outdoor pollutants (Han et al., 2015; Ji and Zhao, 2015; Massey et al., 2013). For example, indoor $\mathrm{PM}_{2.5}$ concentrations in an apartment in Beijing were significantly correlated with those immediately outside with a lag time of 75-115 min (Han et al., 2015). A survey of multiple households conducted in Beijing also reported that $54-63 \%$ of the $\mathrm{PM}_{2.5}$ detected in indoor air was from outdoors when all windows were closed, and the percentage reached 92\% with all windows open (Ji and Zhao, 2015).

The indoor environment can also be directly affected by the behavior of the residents, and the most important internal source is solid fuel combustion for cooking and heating. For example, it was reported that $\mathrm{PM}_{2.5}$ concentrations in a rural household in northern China were one order of magnitude higher than those immediately outside (Zhong et al., 2012). Other common sources include smoking, cooking fumes, and many other human activities (Abt et al., 2000; Kearney et al., 2014; Massey et al., 2016; Pagel et al., 2016). On the other hand, air cleaners that are designed and deployed to remove $\mathrm{PM}_{2.5}$ from indoor air are becoming popular in Beijing.

A series of sophisticated process models have been successfully developed to quantify the exchange of air pollutants between indoor and outdoor environments based on detailed household parameters. Hodas et al. (2015) have reviewed the literature on various factors affecting indoor air quality in various indoor environments and geographic regions, focusing on parameters associated with building characteristics, occupant characteristics and behaviors, and pollutant properties. Zhao et al. (2010) have developed and compared an analytical model, a Eulerian model, and a Lagrangian model for predicting particle penetration coefficients through a single straight crack in building envelops. And it was found that all the three models match well with particles sizes ranging from 0.4 to $1.2 \mu \mathrm{m}$ while the Eulerian approach agree best for the entire range of particle sizes. However, it is difficult to apply a process model on a large scale for population level exposure assessments because of variability in household settings. In some studies, the relationship between indoor and outdoor $\mathrm{PM}_{2.5}$ concentrations were simply quantified by calculating indoor/outdoor concentration ratios $(\mathrm{I} / \mathrm{O})(\mathrm{Li}, 1994)$.

In this study, simultaneous measurements of $\mathrm{PM}_{2.5}$ in indoor and outdoor air were conducted for 13 households in Haidian, Beijing to investigate the dependence of indoor air $\mathrm{PM}_{2.5}$ concentrations on those of ambient air. The influences of cooking fumes and air cleaners were also addressed. The quantified relationship was then applied to estimate the overall population exposure to $\mathrm{PM}_{2.5}$ in Haidian and the associated health consequences by considering both the indoor and outdoor concentrations.

\section{Methodology}

\subsection{Study area and sites}

Haidian is one of the central districts of Beijing. The southeast of the district accommodates the majority of the 3.7 million people in Haidian, while the northwest area is mountainous. A total of 13 volunteers were recruited for on-site PM measurements in their apartments, which are representative of housing in Beijing. Among them, 11 were located in southeast of Haidian, while the other two were in the neighboring area to the east and south (Fig. S1). For all the apartments tested, pipelined natural gas was used for cooking, ventilation fans were installed in the kitchens, and winter heating was supplied by centralized heating systems. Since there was no significant difference in the measured results between the two apartments outside of Haidian and those in Haidian, all data were used in the analysis. All the dwellings were ventilated by open windows during the experimental period. More descriptions of the apartments are listed in Table S1. With limited sampling size, sources other than cooking and incense burning such as smoking were avoided on purpose.

\subsection{Instruments and calibration}

For each apartment, two sets of 4-to-1 particle counters (sixchannel, CEM DT9880/9881, Shenzhen, China) and a two-channel temperature/humidity recorder (Wangyunshan WTH0T1-2-0.5, Fuzhou, China) were deployed for simultaneous measurement of the PM, temperature, and relative humidity both indoors and outdoors. A total of 16 counters were used and the durations of the measurements for individual sites depend on the availability. The indoor sensors were deployed approximately $1.5 \mathrm{~m}$ high, while the outdoor sensors were outside of the window. The particle counter provided six size bins $(0.3-0.5,0.5-1.0,1.0-2.5,2.5-5.0,5.0-10.0$, and $>10 \mu \mathrm{m}$ ), which could be transformed into $\mathrm{PM}_{2.5}$ mass concentrations based on the result of a calibration experiment. All devices were operated for two weeks at the Research Center for Eco-Environmental Sciences, CAS, and the data were calibrated against the daily $\mathrm{PM}_{2.5}$ concentrations from Wanliu Station, a routine monitoring station in Haidian operated by the Beijing Municipal Environmental Monitoring Center. A general relationship was derived as $P M_{\text {mass }}=a P M^{b}{ }^{b}$ num, where $P M_{\text {mass }}$ and $P M_{\text {num }}$ are mass (from Wanliu) and number (from the instruments) concentrations, respectively; $a$ and $b$ are fitted regression coefficients, which are device dependent. A similar relationship has been reported previously (Dacunto et al., 2015). For all devices calibrated, the $R^{2}$ of the calibration curves varied between 0.88 and 0.96 , indicating the procedure was generally satisfactory.

\subsection{Questionnaire and monitoring}

Informed consent was obtained for all sites. A questionnaire with basic information about the apartment and daily activities was completed at each site. The measurements were conducted both for non-heating (April to August) and heating (November to December) seasons. The original design was to separate summer and spring to include the spring sandstorm. With no significant differences in the measurements between the two seasons (no sandstorm during the experiment), the data were combined into one non-heating season. The measurements lasted for 9-37 days with 10-min intervals.

\subsection{Exposure quantification}

The overall exposures of the Haidian population to $\mathrm{PM}_{2.5}$ were calculated based on indoor and ambient $\mathrm{PM}_{2.5}$ concentrations and the average time the residents spent indoors and outdoors (Duan, 2013). The ambient $\mathrm{PM}_{2.5}$ concentrations in 2015 were directly from the Wanliu station. The indoor concentrations were calculated for heating (four months, Jan. 1st - March 15th and Nov. 15th to Dec. 31st, 2015) and non-heating seasons using two regression models developed in this study based on the results of the simultaneous measurements. Monte Carlo simulation was conducted to generate a distribution, instead of a single value, for the exposure concentrations. 


\subsection{Health risk assessment}

Integrated exposure-response models (IERs) were adopted to estimate the $\mathrm{PM}_{2.5}$ exposure-induced relative risks (RRs) for lung cancer (LC), cerebrovascular disease (stroke), and ischemic heart disease (IHD) among the population in Haidian (Burnett et al., 2014). The population attributable fraction of each disease was calculated based on RRs (Lim et al., 2012). To characterize the health loss attributable to $\mathrm{PM}_{2.5}$ exposure, premature deaths and DALYs for individual diseases were calculated using an equation from the literature (Ostro, 2004). Background deaths and DALYs for all ages and both genders in Beijing were from GBD 2013 (GBD, 2013, 2016).

\subsection{Data analysis}

SPSS 22.0 (SPSS Inc., NY, USA) was used for most statistical analysis. TableCurve 2D v.5.01 (Systat Software Inc., CA, USA) and OriginPro 8.1 (OriginLab Corp., MA, USA) were used to establish conversion formulas to convert $\mathrm{PM}_{2.5}$ number concentrations to mass concentrations. A bimodal distribution was tested and fitted for the measured $\mathrm{PM}_{2.5}$ concentrations using PeakFit v.4.12 (Systat Software Inc., CA, USA). Monte Carlo simulation (1000 times) was applied to characterize uncertainties of the calculated exposure concentrations and health endpoints. The results are presented as the ranges between the 25th and 75th percentiles of the derived distributions.

\section{Results and discussions}

\subsection{The observed $P M_{2.5}$ concentrations}

The measured daily mean concentrations of ambient air $\mathrm{PM}_{2.5}$ using the simple devices were calibrated against those reported for Wanliu Station (Fig. S2). It appears that the devices performed well, with a mean relative error of $26.7 \pm 25.4 \%$. The largest differences were found when the ambient $\mathrm{PM}_{2.5}$ concentrations were above $320 \mu \mathrm{g} / \mathrm{m}^{3}$, which is roughly the upper limit of the linear response range. Fortunately, only $1.0 \%$ of the data were above this limit, and their effect on the data analysis was therefore limited.

During the study period, the means and standard deviations of the daily $\mathrm{PM}_{2.5}$ concentrations in ambient air were $110 \pm 103 \mu \mathrm{g} / \mathrm{m}^{3}$ and $42 \pm 50 \mu \mathrm{g} / \mathrm{m}^{3}$ for the heating and non-heating seasons, respectively. The average concentration in the heating season was almost three times that in the non-heating season. Similar seasonal differences are often reported for northern Chinese cities ( $F$. Huang et al., 2015; Liang et al., 2015; Zhou et al., 2015) because of coal burning for heating. Although many residential coal stoves have been replaced with natural gas and centralized heating systems in the downtown area, millions of rural-to-urban migrants use coal for both cooking and heating (Ru et al., 2015), and solid fuels are extensively used in the surrounding rural areas (Chen et al., 2016). Another possible reason is that stagnant weather occurs more frequently in winter (Song et al., 2006). Similarly, the mean $\mathrm{PM}_{2.5}$ concentration of indoor air in the heating season $\left(64 \pm 70 \mu \mathrm{g} / \mathrm{m}^{3}\right)$ was higher than that in the non-heating season $\left(33 \pm 40 \mu \mathrm{g} / \mathrm{m}^{3}\right)$. Similar results of $44 \pm 28$ and $69 \pm 38 \mu \mathrm{g} / \mathrm{m}^{3}$ for indoor and outdoor $\mathrm{PM}_{2.5}$ concentrations in summer have been reported previously (L. Huang et al., 2015). In fact, relatively low concentrations for indoor air were observed at almost all individual sites (Fig. S3).

Ambient $\mathrm{PM}_{2.5}$ concentrations are often found to be lognormally distributed (World Health Organization, 2006). However, bimodal distributions were found for both indoor and outdoor $\mathrm{PM}_{2.5}$ concentrations in both seasons in this study (Fig. S4). It is believed that rapid accumulation of fine particles under stagnant conditions and rapid cleanup by north winds lead to abrupt alternations between severely polluted situations and clean events in Beijing (Han et al., 2015). The two populations, which can be quantitatively distinguished from the bimodal distribution, represent polluted and clean periods, respectively. The mean $\mathrm{PM}_{2.5}$ concentrations were $33.2 \pm 3.3$ and $208.4 \pm 3.3 \mu \mathrm{g} / \mathrm{m}^{3}$ for the two conditions in the heating season, which were larger than $8.9 \pm 6.2$ and $119.1 \pm 6.2 \mu \mathrm{g} / \mathrm{m}^{3}$ for the two corresponding conditions in indoor air.

\subsection{Relationship between indoor and outdoor $P M_{2.5}$}

If there are no strong emission sources in a household, the $\mathrm{PM}_{2.5}$ in indoor air is expected to originate from penetration of $\mathrm{PM}_{2.5}$ from ambient air (Ji and Zhao, 2015). Indoor $\mathrm{PM}_{2.5}$ concentrations can also be affected by internal sources, such as cooking, smoking, and even secondary organic aerosol formation (Abt et al., 2000; Ji and Zhao, 2015). To address the influence of ambient air $\mathrm{PM}_{2.5}$, the data excluding those obviously affected by cooking, incense burning, and air cleaner using are discussed in this section, while the internal influences are characterized in the next section.

Fig. 1 illustrates typical examples of synchronous variations of indoor (data affected by internal sources are excluded) and outdoor $\mathrm{PM}_{2.5}$ concentrations for the non-heating (from July 30 to Aug. 9) and heating seasons (from Dec. 4 to 16). Similar trend was found for other periods not shown. For both indoor and outdoor air, especially the outdoor air, steep changes between high and low $\mathrm{PM}_{2.5}$ concentrations can be observed, confirming the explanation given for the bimodal distribution. For example, the $\mathrm{PM}_{2.5}$ concentration dropped by a factor of 64 , from 174 to $2.7 \mu \mathrm{g} / \mathrm{m}^{3}$, during a short period of two hours on Aug. 5. Similarly, the $\mathrm{PM}_{2.5}$ concentrations dropped by a factor of 33, from 265 to $8.8 \mu \mathrm{g} / \mathrm{m}^{3}$, within $1.3 \mathrm{~h}$ on Dec. 14. Both the rapid accumulation of secondary aerosols under favorable conditions and fast cleanup by north or northwest winds in Beijing have been reported (Han et al., 2015).

Similar to the mean concentrations, the recorded 10-min interval data for outdoor $\mathrm{PM}_{2.5}$ concentrations were generally higher than those for indoor air. For example, during severe pollution episodes from Nov. 28 to Dec 2, the $\mathrm{PM}_{2.5}$ concentrations in ambient air were as high as $300-550 \mu \mathrm{g} / \mathrm{m}^{3}$, while the corresponding indoor $\mathrm{PM}_{2.5}$ concentrations varied between 150 and $350 \mu \mathrm{g} / \mathrm{m}^{3}$. The Spearman correlation coefficients between indoor and outdoor $\mathrm{PM}_{2.5}$ concentrations were 0.946 and $0.921(p<0.05)$ for the non-heating and heating periods, respectively, indicating the strong association between them. As expected, the differences between indoor and outdoor $\mathrm{PM}_{2.5}$ concentrations were relatively high in the heating season when most windows are closed, preventing thorough air exchange and rapid penetration.

Further evidence of the dependence of indoor $\mathrm{PM}_{2.5}$ concentration on the ambient concentration is the lag of the indoor $\mathrm{PM}_{2.5}$ concentrations behind those in ambient air, which can be confirmed by a lag correlation analysis as shown by Han et al. (2015). The correlation coefficients were calculated by shifting outdoor $\mathrm{PM}_{2.5}$ concentrations backwards stepwise in 10-min intervals and the calculated correlation coefficients were plotted against the shifting time as in Fig. 2. The mean lag times were defined as the time shifts that yielded the maximum coefficients. For the non-heating season, the average lag time was $12 \pm 12 \mathrm{~min}$, much shorter than $78 \pm 19 \mathrm{~min}$ in the heating season. The penetration in the non-heating season is faster when windows are open more often. In addition to the difference in the mean lag time, the variation in lag time among individual households was significantly higher during the non-heating season than during the heating season. The calculated coefficients of variance of lag times were $100 \%$ and $24 \%$ for the non-heating and heating periods, respectively, because most, if not all, windows were tightly closed in cold 

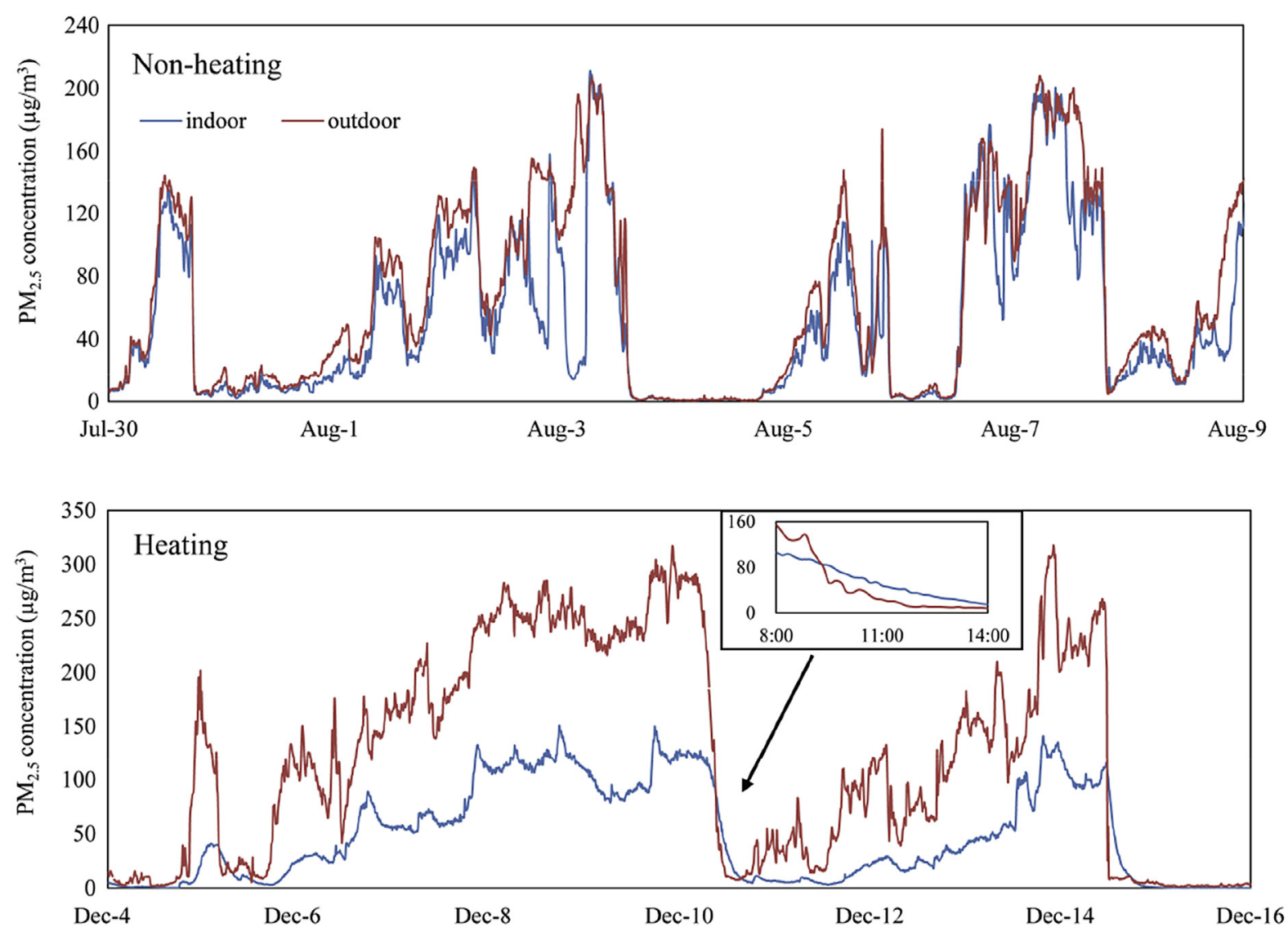

Fig. 1. Time series of indoor and outdoor $\mathrm{PM}_{2.5}$ concentrations for the non-heating (top panel) and heating (bottom panel) seasons.
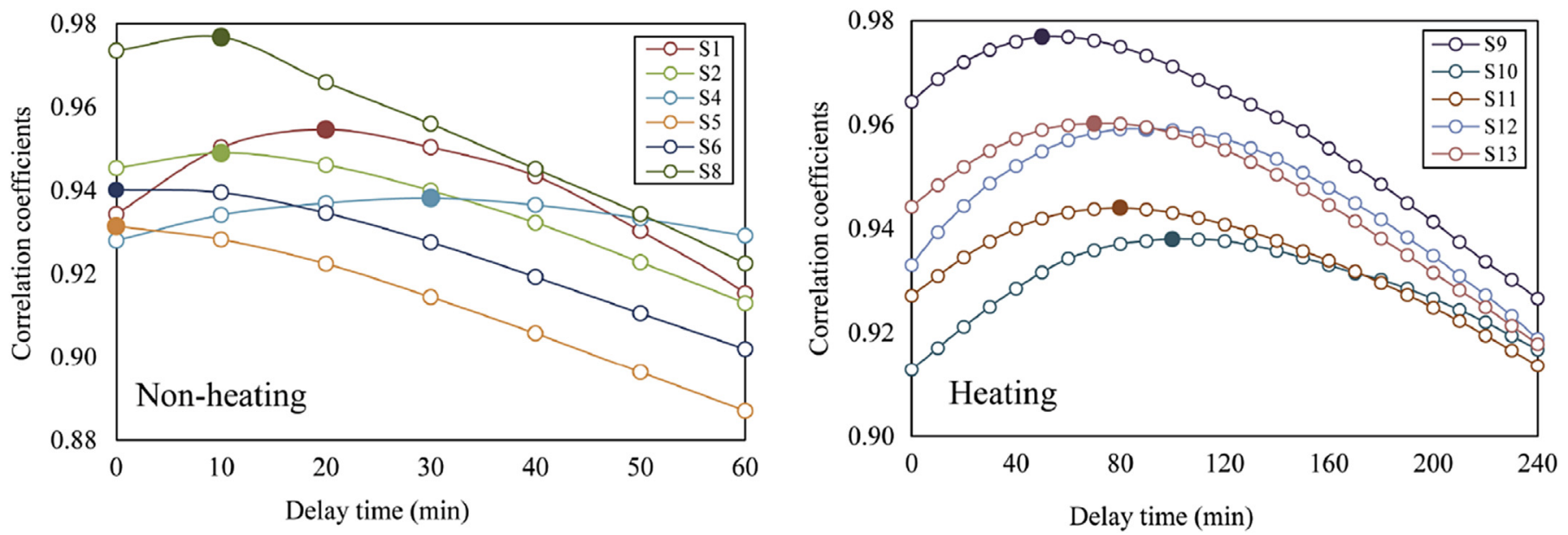

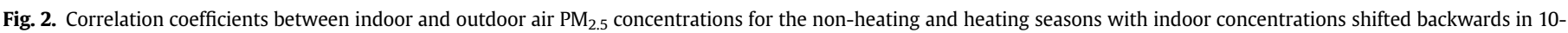
min intervals. The peak time of a curve is defined as the lag time.

winter for all households studied, while the window opening frequencies varied among households in the non-heating seasons.

The indoor $\mathrm{PM}_{2.5}$ concentrations measured for all households during the entire study period excluding those under influences of internal activities are plotted against those of the outdoor $\mathrm{PM}_{2.5}$ concentrations in Fig. S5, with (right panel) or without (left panel) lag justification using the mean lag time. Although the indoor and outdoor $\mathrm{PM}_{2.5}$ concentrations were significantly correlated in both cases $(p<0.05)$, the correlation coefficient with lag justification
(0.96) was slightly higher than that without (0.93). Moreover, the lag justification resulted in a reduced intercept, indicating a better fitting of the results. Although the $\mathrm{PM}_{2.5}$ concentrations in indoor air were mostly lower than those in outdoor air, $16 \%$ of the data points, most of which were for low concentrations, fell above the 1:1 line after the justification. By examining the detailed synchronous variations, it was found that many of these data occurred when the outdoor concentrations dropped rapidly to very low levels near the end of a heavy pollution episode, while the indoor 
concentrations responded slowly to this change and remained relatively high due to the indoor-outdoor lagging effect (Fig. 1).

Both temperature and relative humidity were measured in this study. To identify possible influences of these parameters on penetration of outdoor $\mathrm{PM}_{2.5}$, the differences between indoor and outdoor $\mathrm{PM}_{2.5}$ concentrations were plotted against relative humidity as in Fig. S6. The differences were positively correlated $(p<0.05)$ with relative humidity for both heating $(r=0.288)$ and non-heating seasons $(r=0.265)$. Although humidity is unlikely to affect air exchange directly, high humidity in Beijing is often associated with stagnant conditions and consequently low wind speed, which was not measured in the study. Another finding is that the lag time was negatively correlated with outdoor temperature, and the correlations were significant $(p<0.05)$ for both the heating and non-heating seasons. The temperature dependence within a season is likely due to the same reason causing the difference in lag time between the two seasons.

The particle counters simultaneously recorded particle numbers of six size fractions, allowing a size comparison between indoor and outdoor air. Fig. 3 shows the portions of the smallest size $(0.3-0.5 \mu \mathrm{m})$ fraction $\left(F_{0.3-0.5}\right)$ in indoor and outdoor air for both heating and non-heating seasons as functions of ambient air $\mathrm{PM}_{2.5}$ concentrations in log-scale. $\mathrm{F}_{0.3-0.5}$ in both outdoor and indoor air dropped dramatically when the ambient $\mathrm{PM}_{2.5}$ concentrations exceeded approximately $100 \mu \mathrm{g} / \mathrm{m}^{3}$ for both seasons. It appears that the heavily polluted episodes were characterized by rapid formation of relatively coarse secondary aerosols. It has been previously reported that fine mode peaks of PM in ambient air in
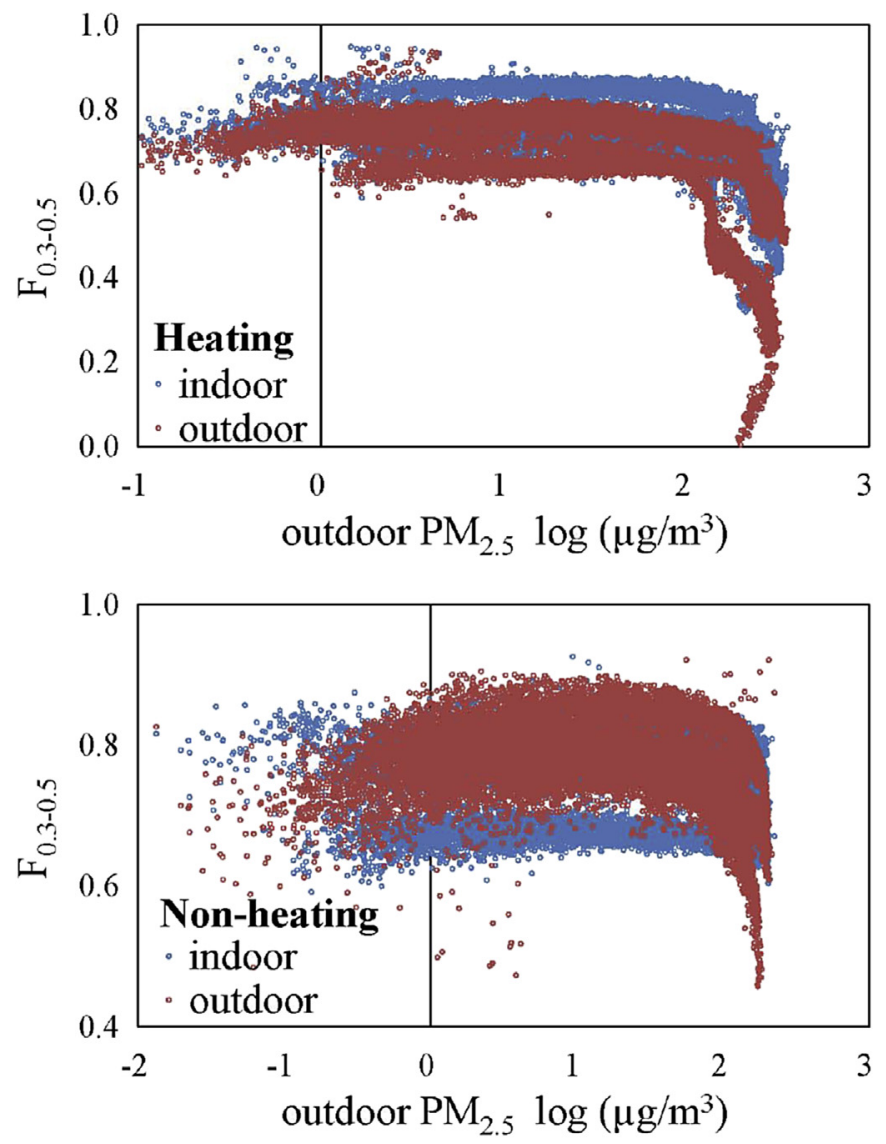

Fig. 3. Fractions of particles with sizes between 0.3 and 0.5 and $0.5-10 \mu \mathrm{m}$ in indoor and outdoor air in the non-heating (bottom panel) and heating (top panel) seasons as functions of $\mathrm{PM}_{2.5}$ concentrations in ambient air in log-scale.
Beijing were approximately $0.32-0.56 \mu \mathrm{m}$ on regular days and shifted to $1.0-1.8 \mu \mathrm{m}$ on hazy days (Sun et al., 2015). It was also found that there were significant differences in $\mathrm{F}_{0.3-0.5}$ between indoor and outdoor air and the differences were opposite in the two seasons. In the non-heating season, the $\mathrm{F}_{0.3-0.5}$ in indoor air $(0.75 \pm 0.08)$ was significantly smaller than that in outdoor air $(0.78 \pm 0.06)$ (paired test, $p<0.05$ ), while in the heating season $\mathrm{F}_{0.3-}$ 0.5 in indoor air $(0.73 \pm 0.08)$ was much larger than that in outdoor air $(0.66 \pm 0.12)$ (paired test, $p<0.05)$. It appears that fine particles penetrate into indoor environment relatively easily through window cracks in the winter when all windows are closed. In summer, however, large particles can easily pass into indoor air through open windows.

\subsection{Influence of indoor activities}

As discussed above, when the ambient $\mathrm{PM}_{2.5}$ concentrations dropped rapidly after a severe pollution episode, the trend in the indoor environment lagged behind, resulting in relatively higher concentrations of $\mathrm{PM}_{2.5}$ in indoor air. However, not all situations when $\mathrm{PM}_{2.5}$ concentrations were higher indoors than outdoors can be explained by this lagging phenomenon. In fact, indoor emissions due to human activities are also important reasons. For example, during an on-site PM monitoring campaign for seven consecutive days reported previously, relatively high $\mathrm{PM}_{2.5}$ concentrations in indoor air during cooking, cleaning, and incineration activities were observed (Pagel et al., 2016). It was also found that exposure to $\mathrm{PM}_{2.5}$ by an average household member could be doubled due to cooking (Shrubsole et al., 2012). Similar phenomena were found in this study. For instance, it was found that cooking activity can generate sharp but narrow additive pulse peaks to the baseline curves. Three such peaks for one lunch and two dinner preparations during a two-day monitoring period in one household are shown in Fig. 4 (curves) as typical examples. The peak concentrations varied from several to more than 10 times the baseline values, reaching concentrations of $189-238 \mu \mathrm{g} / \mathrm{m}^{3}$. The starting and ending times of the cooking were readily identified and each processes lasted around 30-60 min. The beginning of the cooking corresponded to a sudden jump of the concentration, while the end of cooking was followed by a short tailing period. In the studied household, the cooking was done using piped natural gas, which does not emit much particulate pollution. The major source of the particles

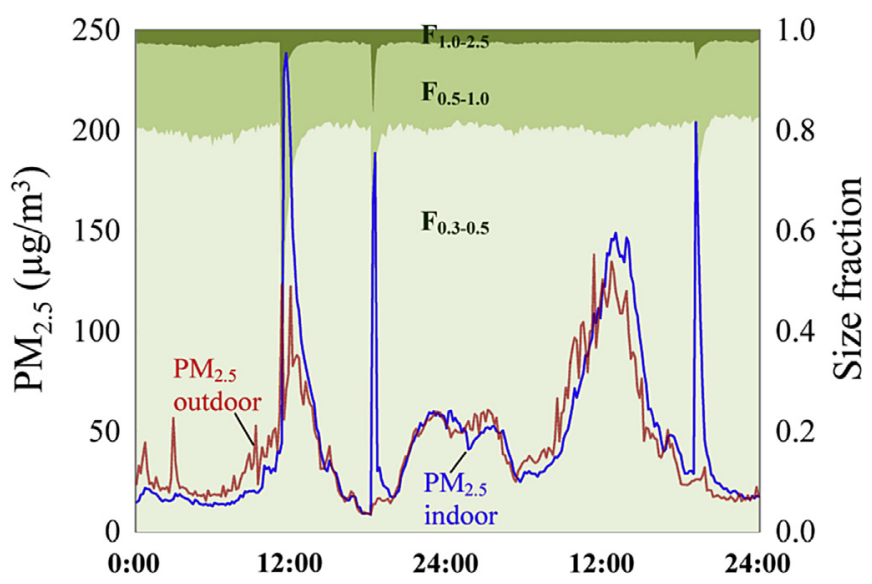

Fig. 4. Temporal variations of $\mathrm{PM}_{2.5}$ concentrations in both indoor and outdoor air (lines) and relative contributions of six size fractions in indoor air (areas) during a twoday monitoring period with three cooking activities. The measurement was conducted from April 25 to 26 . The relative contributions of the two course size fractions are too small to show. 
observed was from cooking fumes generated from overheated vegetable oil, which is typical in the preparation of Chinese dishes.

The cooking activity affected not only the concentration of $\mathrm{PM}_{2.5}$ but also the size distribution of the particles detected. The time series of the relative contributions of six size fractions in indoor air to the total $\mathrm{PM}_{2.5}$ concentrations over the two-day period with three cooking activities recorded are shown in Fig. 4 (areas). At the time of the three sharp peaks of $\mathrm{PM}_{2.5}$ concentrations that occurred during cooking, $\mathrm{F}_{0.3-0.5}$ decreased dramatically, together with significant increases in the $0.5-2.5 \mu \mathrm{m}$ fractions, particularly the $0.5-1.0 \mu \mathrm{m}$ particles, indicating relatively coarse particles emitted in cooking fumes.

The relative contributions of cooking fumes to indoor air pollution depend on baseline concentrations. In the case of the particular example shown in Fig. 4, the baseline $\mathrm{PM}_{2.5}$ concentrations were generally low $\left(42.0 \pm 31.9 \mu \mathrm{g} / \mathrm{m}^{3}\right)$, resulting in three sharp peaks during the cooking. Even in this relatively clean situation, the contribution of cooking fumes was rather small because they occurred for a relatively short period of time. The indoor $\mathrm{PM}_{2.5}$ concentrations recorded in this study were generally higher than those observed in this example, making the overall relative contribution of cooking emissions even smaller. It appears that under the current circumstances in Haidian, and very likely in other urban districts of Beijing, the major source of household air pollution is the penetration of the particles from the ambient environment, which is often severely polluted, with annual mean concentrations of $\mathrm{PM}_{2.5}$ as high as $80.6 \mu \mathrm{g} / \mathrm{m}^{3}$ in 2015 (Beijing Municipal Environmental Protection Bureau, 2016).

Another example of an indoor emission was incense burning, shown in Fig. S7 (left panel). While the ambient $\mathrm{PM}_{2.5}$ concentrations varied between 10 and $40 \mu \mathrm{g} / \mathrm{m}^{3}$, two peaks caused by incense burning, as recorded by the residents, were observed and the concentrations rose to $50-60 \mu \mathrm{g} / \mathrm{m}^{3}$, well above the baseline, and the influence lasted for $2-3 \mathrm{~h}$ each time. In addition to cooking and incense burning, many other indoor activities such as walking, dusting, or even sitting down on upholstered furniture can lead to re-suspension and enhanced concentrations of PMs, especially in poorly ventilated environments (Qian et al., 2014). Such influences often occurred randomly and weakly and could be seen only when the background concentrations were very low. A typical example is shown in Fig. S7 (right panel) when ambient air concentrations were extremely low, resulting in relatively high $\mathrm{PM}_{2.5}$ concentrations in indoor air.

Among all the sites investigated in this study, there happened to be one household using an air cleaner (S7). The data for this household were not included in the previous discussion and are used here to address the influence of the air cleaner. In Fig. S8, the data for the household using an air cleaner are included as green dots, with the other data in blue. Although the measurements in the particular household were conducted during a period with relatively low concentrations of ambient air $\mathrm{PM}_{2.5}$, the effectiveness of the equipment can be clearly seen. The slope of a force-to-origin regression using all data with the air cleaner on is 0.18 , compared to 0.62 based on all other data within the same range, suggesting an average $71 \%$ removal efficiency within this range. Unfortunately, the data for severely polluted days were not available and only a single household was tested. In the future, a well designed field study is recommended to specifically address the effectiveness of household air cleaners in reducing exposure in indoor environments in severely polluted cities.

\subsection{Quantification of indoor air $P M_{2.5}$}

Indoor/outdoor $(\mathrm{I} / \mathrm{O})$ ratios are often used as indicators representing the relationship between indoor and outdoor pollutant concentrations. The ratios vary extensively depending on many factors including sampling locations and procedures, analytical methods, building configuration and ventilation, internal emission sources, and meteorological conditions (Chen et al., 2011; Massey et al., 2009; Zhao et al., 2015). According to a thorough review, it was found that the reported $\mathrm{I} / \mathrm{O}$ varied over three orders of magnitude, from 0.02 to 31, with an $\mathrm{I} / \mathrm{O}$ above one often associated with solid fuel burning (Chen et al., 2011). Without major internal sources of solid fuel burning, the measured mean and three quartiles of $\mathrm{I} / \mathrm{O}$ in this study were $0.88,0.42,0.63$, and 0.87 , with $82 \%$ of the $\mathrm{I} / \mathrm{O}$ values less than one. On a daily basis, the mean $\mathrm{I} / \mathrm{O}$ values were $0.88 \pm 0.56$ and $0.53 \pm 0.35$ for the non-heating and heating periods, respectively. The frequency distributions of the calculated $\mathrm{I} / \mathrm{O}$ for individual measurements with or without lag justification are shown in Fig. S9 in log-scale. Both distributions were leptokurtic even after the log-transformation.

A key objective of this study was to establish an applicable model to predict indoor $\mathrm{PM}_{2.5}$ concentration based on outdoor data, which are readily available and can be modeled on a regional scale. Regression analysis was conducted for this purpose. Although simple linear regression models with lag time incorporated can explain $86 \%$ and $84 \%$ of the variations for the non-heating (the slope and intercept were 0.9016 and 0.0153 , respectively) and heating (the slope and intercept were 1.0221 and -0.3798 , respectively) seasons, respectively, there are clear trends that underestimate indoor air $\mathrm{PM}_{2.5}$ levels at the high concentration range. This bias can be avoided by using non-linear exponential models. The models developed based on the training data sets (80\%, randomly selected) with average lag time taken into consideration are as follows:

$\lg P M_{2.5}(\mathrm{I})=-3.566+3.610 e^{\lg P M_{2.5}(0-10) / 4.91}$

$R^{2}=0.867$, the non - heating season

$\lg P M_{2.5}(\mathrm{I})=-1.385+1.240 e^{\lg P M_{2.5}(\mathrm{O}-80) / 2.27}$

$R^{2}=0.861$, the heating season

where $P M_{2.5}(\mathrm{I})$ is the indoor air $\mathrm{PM}_{2.5}$ concentration and $P M_{2.5}(\mathrm{O}$ 10) and $P M_{2.5}(\mathrm{O}-80)$ are the outdoor $\mathrm{PM}_{2.5}$ concentrations with 10 and $80 \mathrm{~min}$ of lag time, respectively. The fitting results are shown in Fig. 5 (top panels) for both non-heating and heating seasons. More than $86 \%$ of the variations can be explained for both models. The slope is significantly lower $(p<0.05)$ for the heating season when all windows were closed. The models were validated using the remained $20 \%$ data in the validation data sets (Fig. 5, bottom panels), showing no bias. The calculated mean residues were 1.46 and $3.07 \mu \mathrm{g} / \mathrm{m}^{3}$ and $75.0 \%$ and $74.5 \%$ of the data points fall within $\pm 60 \%$ limits for the two models, indicating a good agreement between the predictions and observations. The regression was conducted ten times and the average mean residues were $1.50 \pm 14.73$ and $4.95 \pm 28.29 \mu \mathrm{g} / \mathrm{m}^{3}$ for the two seasons, indicating high robustness of the models.

It appears that $\mathrm{PM}_{2.5}$ concentrations in indoor air can be derived with reasonable accuracy. Of course, with limited measurements taken, the limitations of the models are obvious. With more information on detailed indoor activities and the influences of meteorological conditions, as well as more extensive observations, the models can be further improved.

\subsection{Exposure estimation and health risks}

A number of studies have been conducted to quantify the impacts of $\mathrm{PM}_{2.5}$ on health based only on ambient air $\mathrm{PM}_{2.5}$ 

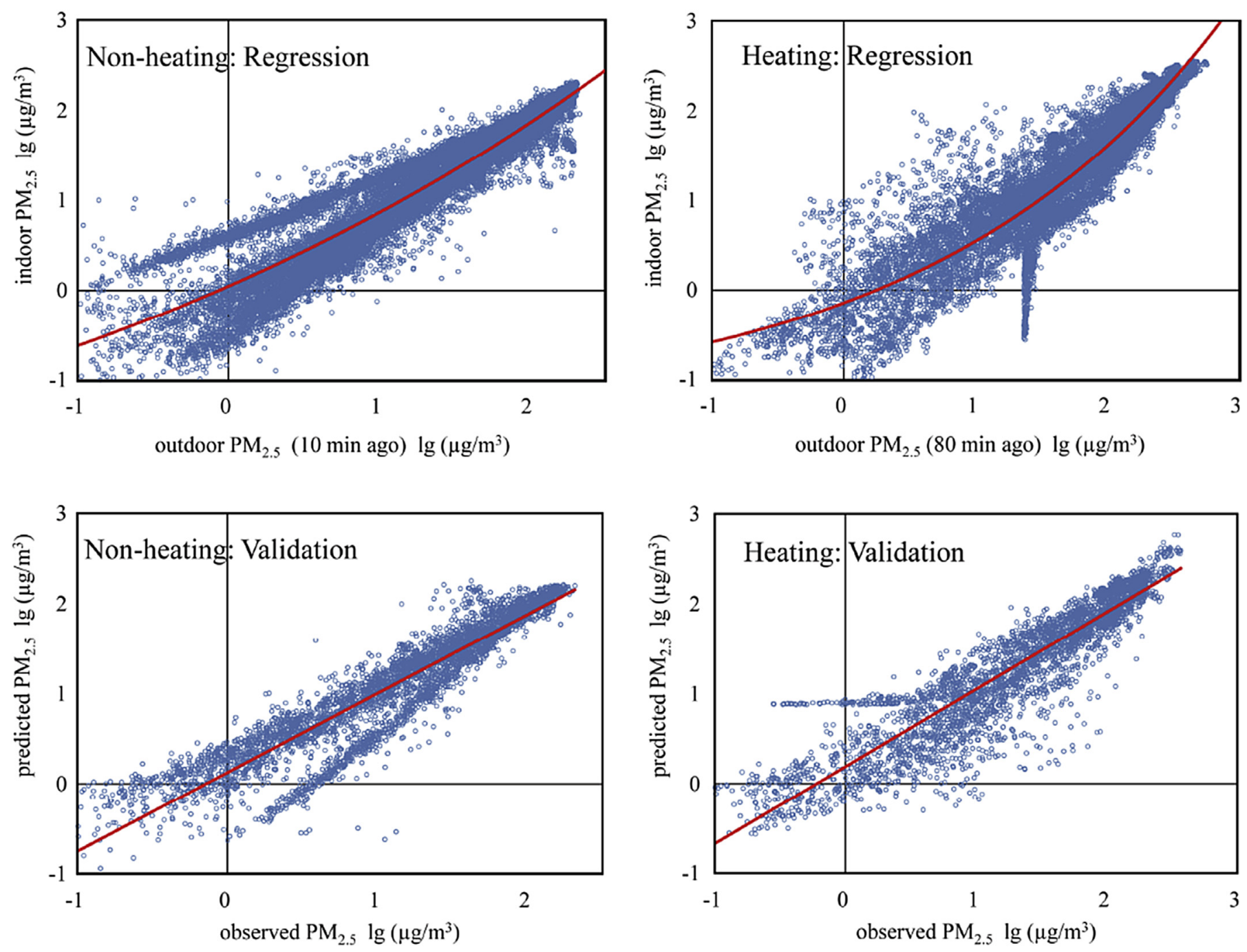

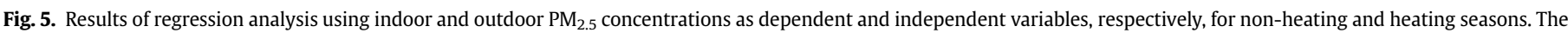
exponential models were developed based on training data (top panels) and validated against validating data (bottom panels).

concentrations because of a lack of indoor data (Guo et al., 2016; Qian et al., 2016; Zheng et al., 2015). Because the population in Beijing spends more than $80 \%$ of its time indoors, a bias in estimation is inevitable without taking indoor air quality into consideration. Based on the results presented above, we were able to reevaluate the exposure of local residents to $\mathrm{PM}_{2.5}$ and thus gauge the consequent health impact as part of an integrated risk assessment.

Based on the reported ambient $\mathrm{PM}_{2.5}$ concentrations in the Haidian District, the calculated indoor air $\mathrm{PM}_{2.5}$ concentrations, the length of heating season (Nov. 15 to March 15), time spent indoors (Duan, 2013), the dose-response relationships for a number of diseases (Burnett et al., 2014) and the local death rate, annual exposure doses and the resulting health impacts for 2015 were quantified using a Monte Carlo simulation. Fig. S10 shows the calculated frequency distribution of annual mean exposure to $\mathrm{PM}_{2.5}$ concentrations of the studied population. The mean and standard deviation were $51.0 \pm 11.9 \mu \mathrm{g} / \mathrm{m}^{3}$ (without air cleaner). The corresponding RRs were 1.30 (1.06-1.54 as the 95\% confidence interval), 1.36 (1.20-1.74), and $1.69(1.15-2.22)$ for LC, IHD, and stroke, respectively. If the indoor air concentrations were substituted with ambient values, the mean exposure concentrations would be $81.0 \pm 1.65 \mu \mathrm{g} / \mathrm{m}^{3}$, indicating a $58.9 \%$ overestimation. Similarly, the overestimation of $R R$ s would be $11.1 \%, 6.4 \%$, and $11.8 \%$, respectively.
The relatively low values in overestimation of $R R$ s compared with the exposure can be explained by the non-linearity of the doseresponse relationships.

Based on the calculated $R R$ s and population data, the premature deaths attributable to $\mathrm{PM}_{2.5}$ exposure in Haidian in 2015 were estimated to be 220 (70-320), 950 (670-1520), and 1240 (430-1690) for LC, IHD, and stroke, respectively. Accordingly, the estimated DALYs attributable to $\mathrm{PM}_{2.5}$ exposure were 3880 (1190-5660), 15,240 (10,760-24,290), and 20,320 (7100-27,650) days for LC, IHD, and stroke, respectively. The total number of premature deaths and DALYs would increase from 2410 to 39,440 to 2780 and 45,540, respectively, if the indoor air concentrations of $\mathrm{PM}_{2.5}$ were simply substituted with the ambient concentrations, indicating approximately $15 \%$ overestimation without taking indoor exposure into consideration. Because of the non-linearity of the dose-response relationship, such differences would be even larger if the ambient $\mathrm{PM}_{2.5}$ concentrations were reduced in the future. As shown in Fig. S11, if the mean $\mathrm{PM}_{2.5}$ concentrations can be reduced to $50 \mu \mathrm{g} / \mathrm{m}^{3}$ by 2020 , as planned by the Beijing municipal government, the calculated DALYs would be overestimated by $44 \%$ if indoor exposure were not taken into account. The overestimation would be $68 \%$ if the long-term goal of $35 \mu \mathrm{g} / \mathrm{m}^{3}$ were achieved by 2030 (Beijing Municipal Government, 2011). 
Using data collected from the household with an air cleaner in operation, the health benefit was quantified by comparison with households without air cleaners. A simple force-to-origin regression model was applied and was used to estimate indoor $\mathrm{PM}_{2.5}$ concentrations with air cleaner with both indoor and ambient exposures taken into consideration. The calculated slope was 0.180 with an assumed coefficient of variance of 30\% for Monte Carlo simulation. The result is presented in Fig. S12 as two frequency distributions of mean exposure concentrations for the households with or without air cleaners. A considerable shift of the exposure towards lower levels is demonstrated. As a result, the annual mean exposure concentration would be reduced 2.1 times, from $51.0 \pm 11.9$ to $24.2 \pm 3.7 \mu \mathrm{g} / \mathrm{m}^{3}$. The corresponding RRs would also be reduced by $11.4 \%, 8.7 \%$, and $22.2 \%$ to $1.15,1.24$, and 1.31 for LC, IHD, and stroke, respectively. It appears that air cleaners can protect residents from $\mathrm{PM}_{2.5}$ exposure. However, with the limited data collected, the estimation can only provide a flavor of the consequence of using air cleaners. Another constraint is that the data were collected during the non-heating season with relatively low ambient $\mathrm{PM}_{2.5}$ concentrations. It is very likely that the removal efficiencies of air cleaners could be nonlinear in terms of $\mathrm{PM}_{2.5}$ concentration. Therefore, more data from a carefully designed field test are definitely needed to achieve a reliable quantitative result.

Using air cleaners in homes has greater health benefits than using masks outdoors, which is currently a common practice in Chinese cities. For many who often use masks outdoors, air clearers are usually not installed in their homes or offices. It was calculated that the reduction of premature deaths and DALYs would be $16.9 \%$, $9.1 \%$, and $12.3 \%$ for LC, IHD, and stroke, respectively, even if a $100 \%$ removal efficiency for the masks can be achieved. In comparison, reduction in LC, IHD, and stroke would reach $42.8 \%, 25.8 \%$, and $41.0 \%$, respectively, if all households in the district were equipped with air cleaners (Fig. S13).

\section{Conclusions}

Indoor $\mathrm{PM}_{2.5}$ concentrations varied synchronously with outdoor ones with a lagging effect, especially in the heating season. In general, indoor $\mathrm{PM}_{2.5}$ concentrations were lower than those in outdoor air, except there was a sharp drop in ambient air concentration or there were strong internal emission sources such as cooking or incense burning. Air cleaners are effective in reducing exposure to $\mathrm{PM}_{2.5}$. The indoor $\mathrm{PM}_{2.5}$ concentrations can be predicted based on ambient measurements. The overall exposure would be overestimated without taking indoor air concentrations into consideration.

\section{Conflict of interest}

The authors declare no competing financial interest.

\section{Acknowledgement}

This work was supported by the National Natural Science Foundation of China (41390240 and 41571130010) and the 111 Project. Help from Mr. J. Li, Y.L. Chen, K. Chen, X.L. Pan, W.M. Si, H.L. Wang, W.G. He, J.J. Wang, S.S. Peng, H.Y. Liu, Y.L. Li, Y. Liu, Q. Nie, X.N. Luo, C.S. Ni, Z.H. Shen, and J.F. Zhang during the field testing is appreciated.

\section{Appendix A. Supplementary data}

Supplementary data related to this article can be found at http:// dx.doi.org/10.1016/j.envpol.2016.10.035.

\section{References}

Abt, E., Suh, H.H., Catalano, P., Koutrakis, P., 2000. Relative contribution of outdoor and indoor particle sources to indoor concentrations. Environ. Sci. Technol. 34, 3579-3587.

Beijing Municipal Environmental Protection Bureau, 2016. Beijing Environmental Statement 2015. http://www.bjepb.gov.cn/bjepb/resource/cms/2014/06/ 2014061911140819230.pdf (accessed 11.08.16.).

Beijing Municipal Government, 2011. Action Plant for Clean Air for Beijing: Mitigation Measures for Air Pollution from 2011 to 2015. http://blog.sina.com.cn/s blog e54c556f0101fdpj.html (accessed 11.08.16.).

Burnett, R.T., Pope, C.A., Ezzati, M., Olives, C., Lim, S.S., Mehta, S., Shin, H.H., Singh, G., Hubbell, B., Brauer, M., Anderson, H.R., Smith, K.R., Balmes, J.R., Bruce, N.G., Kan, H.D., Laden, F., Pruss-Ustun, A., Michelle, C.T., Gapstur, S.M. Diver, W.R., Cohen, A., 2014. An integrated risk function for estimating the global burden of disease attributable to ambient fine particulate matter exposure. Environ. Health Perspect. 122, 397-403.

Chen, F.-L., Vanderpool, R., Williams, R., Dimmick, F., Grover, B.D., Long, R., Murdoch, R., 2011. Field evaluation of portable and central site PM samplers emphasizing additive and differential mass concentration estimates. Atmos. Environ. 45, 4522-4527.

Chen, Y.L., Shen, H.Z., Zhong, Q.R., Chen, H., Huang, T.B., Liu, J.F., Chen, H.F., Zeng, E.Y. Smith, K.R., Tao, S., 2016. Transition of household cookfuels in China from 2010 to 2012. Appl. Energy. http://dx.doi.org/10.1016/j.apenergy.2016.07.136.

Dacunto, P.J., Klepeis, N.E., Cheng, K.C., Acevedo-Bolton, V., Jiang, R.T., Repace, J.L., Otta, W.R., Hildemann, L.M., 2015. Determining $\mathrm{PM}_{2.5}$ calibration curves for a low-cost particle monitor: common indoor residential aerosols. Environ. Sci. Process Impacts 17, 1959-1966.

Duan, X., 2013. Exposure Factors Handbook of Chinese Population (Adults). China Environmental Science Press, Beijing.

Global Burden of Disease Study 2013, 2016. Global Burden of Disease Study 2013 (GBD 2013) Results by Location, Cause, and Risk Factor. Institute for Health Metrics and Evaluation (IHME), Seattle, United States.

Guo, Y., Zeng, H., Zheng, R., Li, S., Barnett, A.G., Zhang, S., Zou, X., Huxley, R., Chen, W., Williams, G., 2016. The association between lung cancer incidence and ambient air pollution in China: a spatiotemporal analysis. Environ. Res. 144, 60-65.

Han, Y., Qi, M., Chen, Y., Shen, H., Liu, J., Huang, Y., Chen, H., Liu, W., Wang, X., Liu, J., Xing, B., Tao, S., 2015. Influences of ambient air $\mathrm{PM}_{2.5}$ concentration and meteorological condition on the indoor $\mathrm{PM}_{2.5}$ concentrations in a residential apartment in Beijing using a new approach. Environ. Pollut. 205, 307-314.

Hodas, N., Loh, M., Shin, H.M., Li, D., Bennett, D., Mckone, T.E., Jolliet, O., Weschler, C.J., Jantunen, M., Lioy, P., 2015. Indoor inhalation intake fractions of fine particulate matter: review of influencing factors. Indoor Air. http:// dx.doi.org/10.1111/ina.12268.

Huang, F., Li, X., Wang, C., Xu, O., Wang, W., Luo, Y., Tao, L., Gao, O., Guo, J., Chen, S., Cao, K., Liu, L., Gao, N., Liu, X., Yang, K., Yan, A., Guo, X., 2015. PM 2.5 spatiotemporal variations and the relationship with meteorological factors during 2013-2014 in beijing, China. PloS One 10, e0141642.

Huang, L., Pu, Z., Li, M., Sundell, J., 2015. Characterizing the indoor-outdoor relationship of fine particulate matter in non-heating season for urban residences in Beijing. PloS One 10, e0138559.

Institute for Health Metrics and Evaluation (IHME), 2015. GBD Compare. IHME, University of Washington, Seattle, WA. Available from: http://vizhub. healthdata.org/gbd-compare (accessed 11.08.16.).

Ji, W., Zhao, B., 2015. Contribution of outdoor-originating particles, indoor-emitted particles and indoor secondary organic aerosol (SOA) to residential indoor $\mathrm{PM}_{2.5}$ concentration: a model-based estimation. Build. Environ. 90, 196-205.

Kearney, J., Wallace, L., MacNeill, M., Héroux, M.-E., Kindzierski, W., Wheeler, A., 2014. Residential infiltration of fine and ultrafine particles in Edmonton. Atmos. Environ. 94, 793-805.

Lepeule, J., Laden, F., Dockery, D., Schwartz, J., 2012. Chronic exposure to fine particles and mortality: an extended follow-up of the harvard six cities study from 1974 to 2009. Environ. Health Perspect. 120, 965-970.

Li, C.S., 1994. Relationships of indoor outdoor inhalable and respirable particles in domestic environments. Sci. Total Environ. 151, 205-211.

Liang, X., Zou, T., Guo, B., Li, S., Zhang, H., Zhang, S., Huang, H., Chen, S.X., 2015. Assessing Beijing's $\mathrm{PM}_{2.5}$ pollution: severity, weather impact, APEC and winter heating. Proc. R. Soc. A-Mathematical Phys. Eng. Sci. 471, 20150257.

Lim, S.S., Vos, T., Flaxman, A.D., Danaei, G., Shibuya, K., Adair-Rohani, H., Amann, M., Anderson, H.R., Andrews, K.G., Aryee, M., Atkinson, C., Bacchus, L.J., Bahalim, A.N., Balakrishnan, K., Balmes, J., Barker-Collo, S., Baxter, A., Bell, M.L., Blore, J.D., Blyth, F., Bonner, C., Borges, G., Bourne, R., Boussinesq, M., Brauer, M., Brooks, P., Bruce, N.G., Brunekreef, B., Bryan-Hancock, C., Bucello, C. Buchbinder, R., Bull, F., Burnett, R.T., Byers, T.E., Calabria, B., Carapetis, J., Carnahan, E., Chafe, Z., Charlson, F., Chen, H.L., Chen, J.S., Cheng, A.T.A., Child, J.C., Cohen, A., Colson, K.E., Cowie, B.C., Darby, S., Darling, S., Davis, A., Degenhardt, L., Dentener, F., Des Jarlais, D.C., Devries, K., Dherani, M., Ding, E.L., Dorsey, E.R., Driscoll, T., Edmond, K., Ali, S.E., Engell, R.E., Erwin, P.J., Fahimi, S., Falder, G., Farzadfar, F., Ferrari, A., Finucane, M.M., Flaxman, S., Fowkes, F.G.R., Freedman, G., Freeman, M.K., Gakidou, E., Ghosh, S., Giovannucci, E., Gmel, G., Graham, K., Grainger, R., Grant, B., Gunnell, D., Gutierrez, H.R., Hall, W. Hoek, H.W., Hogan, A., Hosgood, H.D., Hoy, D., Hu, H., Hubbell, B.J., Hutchings, S.J., Ibeanusi, S.E., Jacklyn, G.L., Jasrasaria, R., Jonas, J.B., Kan, H.D., 
Kanis, J.A., Kassebaum, N., Kawakami, N., Khang, Y.H., Khatibzadeh, S., Khoo, J.P., Kok, C., Laden, F., Lalloo, R., Lan, Q., Lathlean, T., Leasher, J.L., Leigh, J., Li, Y., Lin, J.K., Lipshultz, S.E., London, S., Lozano, R., Lu, Y., Mak, J., Malekzadeh, R., Mallinger, L., Marcenes, W., March, L., Marks, R., Martin, R., McGale, P., McGrath, J., Mehta, S., Mensah, G.A., Merriman, T.R., Micha, R., Michaud, C. Mishra, V., Hanafiah, K.M., Mokdad, A.A., Morawska, L., Mozaffarian, D., Murphy, T., Naghavi, M., Neal, B., Nelson, P.K., Nolla, J.M., Norman, R., Olives, C., Omer, S.B., Orchard, J., Osborne, R., Ostro, B., Page, A., Pandey, K.D., Parry, C.D.H., Passmore, E., Patra, J., Pearce, N., Pelizzari, P.M., Petzold, M., Phillips, M.R., Pope, D., Pope, C.A., Powles, J., Rao, M., Razavi, H., Rehfuess, E.A., Rehm, J.T. Ritz, B., Rivara, F.P., Roberts, T., Robinson, C., Rodriguez-Portales, J.A., Romieu, I., Room, R., Rosenfeld, L.C., Roy, A., Rushton, L., Salomon, J.A., Sampson, U., Sanchez-Riera, L., Sanman, E. Sapkota, A., Seedat, S., Shi, P.L., Shield, K. Shivakoti, R., Singh, G.M., Sleet, D.A., Smith, E., Smith, K.R., Stapelberg, N.J.C., Steenland, K., Stockl, H., Stovner, L.J., Straif, K., Straney, L., Thurston, G.D., Tran, J.H., Van Dingenen, R., van Donkelaar, A., Veerman, J.L., Vijayakumar, L., Weintraub, R., Weissman, M.M., White, R.A., Whiteford, H., Wiersma, S.T., Wilkinson, J.D., Williams, H.C., Williams, W., Wilson, N., Woolf, A.D., Yip, P., Zielinski, J.M., Lopez, A.D., Murray, C.J.L., Ezzati, M., 2012. A comparative risk assessment of burden of disease and injury attributable to 67 risk factors and risk factor clusters in 21 regions, 1990-2010: a systematic analysis for the Global Burden of Disease Study 2010. Lancet 380, 2224-2260.

Massey, D., Masih, J., Kulshrestha, A., Habil, M., Taneja, A., 2009. Indoor/outdoor relationship of fine particles less than $2.5 \mu \mathrm{m}\left(\mathrm{PM}_{2.5}\right)$ in residential homes locations in central Indian region. Build. Environ. 44, 2037-2045.

Massey, D.D., Kulshrestha, A., Taneja, A., 2013. Particulate matter concentrations and their related metal toxicity in rural residential environment of semi-arid region of India. Atmos. Environ. 67, 278-286.

Massey, D.D., Habil, M., Taneja, A., 2016. Particulate in different indoor microenvironments-its implications on occupants. Build. Environ. 106, 237-244.

Ostro, B., 2004. Outdoor Air Pollution: Assessing the Environmental Burden of Disease at National and Local Levels. World Health Organization, Geneva (WHO Environmental Burden of Disease Series, No. 5).

Pagel, E.C., Costa Reis Jr., N., de Alvarez, C.E., Santos, J.M., Conti, M.M., Boldrini, R.S., Kerr, A.S., 2016. Characterization of the indoor particles and their sources in an Antarctic research station. Environ. Monit. Assess. 188, 167.

Pope, C.A., Dockery, D.W., 2006. Health effects of fine particulate air pollution: lines that connect. J. Air \& Waste Manag. Assoc. 56, 709-742.
Qian, J., Peccia, J., Ferro, A.R., 2014. Walking-induced particle resuspension in indoor environments. Atmos. Environ. 89, 464-481.

Qian, Z., Liang, S., Yang, S., Trevathan, E., Huang, Z., Yang, R., Wang, J., Hu, K. Zhang, Y., Vaughn, M., Shen, L., Liu, W., Li, P., Ward, P., Yang, L., Zhang, W. Chen, W., Dong, G., Zheng, T., Xu, S., Zhang, B., 2016. Ambient air pollution and preterm birth: a prospective birth cohort study in Wuhan, China. Int. J. Hyg. Environ. Health 219, 195-203.

Ru, M.Y., Tao, S., Smith, K., Shen, G.F., Shen, H.Z., Huang, Y., Chen, H., Chen, Y.L., Chen, X., Liu, J.F., Li, B.G., Wang, X.L., He, C.F., 2015. Direct energy consumption associated emissions by rural-to-urban migrants in Beijing. Environ. Sci. Technol. 49, 13708-13715.

Shrubsole, C., Ridley, I., Biddulph, P., Milner, J., Vardoulakis, S., Ucci, M., Wilkinson, P., Chalabi, Z. Davies, M., 2012. Indoor PM2.5 exposure in London's domestic stock: modelling current and future exposures following energy efficient refurbishment. Atmos. Environ. 62, 336-343.

Song, Y., Zhang, M.S., Cai, X.H., 2006. PM 10 modeling of Beijing in the winter. Atmos. Environ. 40, 4126-4136.

Sun, K., Liu, X., Gu, J., Li, Y., Qu, Y., An, J., Wang, J., Zhang, Y., Hu, M., Zhang, F., 2015. Chemical characterization of size-resolved aerosols in four seasons and hazy days in the megacity Beijing of China. J. Environ. Sci. 32, 155-167.

World Health Organization, 2006. WHO Air Quality Guidelines for Particulate Matter, Ozone, Nitrogen Dioxide and Sulfur Dioxide. Global update 2005. http:/ whqlibdoc.who.int/hq/2006/WHO_SDE_PHE_OEH_06.02_eng.pdf (accessed 20.01.15.).

Zhao, B., Chen, C., Yang, X.Y., Lai, A.C.K., 2010. Comparison of three approaches to model particle penetration coefficient through a single straight crack in a building envelope. Aerosol Sci. Technol. 44, 405-416.

Zhao, L., Chen, C., Wang, P., Chen, Z., Cao, S., Wang, Q., Xie, G., Wan, Y., Wang, Y. $\mathrm{Lu}, \mathrm{B} ., 2015$. Influence of atmospheric fine particulate matter $\left(\mathrm{PM}_{2.5}\right)$ pollution on indoor environment during winter in Beijing. Build. Environ. 87, 283-291.

Zheng, S., Pozzer, A., Cao, C.X., Lelieveld, J., 2015. Long-term (2001-2012) concentrations of fine particulate matter $\left(\mathrm{PM}_{2.5}\right)$ and the impact on human health in Beijing, China. Atmos. Chem. Phys. 15, 5715-5725.

Zhong J. Ding J., Su, Y, Shen, G, Yang Y, Wang C., Simonich, S.L.M., Cao, H, Zhu, Y, Tao, S., 2012. Carbonaceous particulate matter air pollution and human exposure from indoor biomass burning practices. Environ. Eng. Sci. 29, 1038-1045.

Zhou, B., Shen, H., Huang, Y., Li, W. Chen, H., Zhang, Y., Su, S., Chen, Y., Lin, N., Zhuo, S., Zhong, Q., Liu, J., Li, B., Tao, S., 2015. Daily variations of size-segregated ambient particulate matter in Beijing. Environ. Pollut. 197, 36-42. 